\title{
UK brain-drain 'no worse'
}

London. Britain's brain-drain is not improving. But neither has it been getting much worse, according to a report published in London last week which will provide ammunition both for the government and its critics in the debate over the number of British scientists leaving to work overseas.

The report has already been welcomed by William Waldegrave, the minister for science, who has homed in on its conclusions that there has been a slight fall in the number of scientists emigrating, and a small increase in the number coming to Britain from overseas. In each case, the number remains small compared to the total number of scientists in the United Kingdom.

But those responsible for the report have issued a warning about an excessively complacent interpretation of its conclusion. They point out that it still tends to be the highest quality staff who take posts overseas, confirmed by the growing number of fellows of the society with foreign addresses.

The report has been produced by the Science and Engineering Policy Studies Unit (SEPSU) of the Royal Society. It is based on replies to a questionnaire sent to university science departments, asking for details of individual scientists known to have left the country between 1984 and 1992. Five subject areas were covered: biochemistry, chemistry, Earth sciences, electrical engineering and physics.

The report follows up an earlier version, published in 1987 and covering the period 1975-85, which was the first significant attempt to quantify a phenomenon whose existence tends to be known more through personal anecdote than hard data.

Like the earlier report, the new one points out that, at least in terms of overall figures, the net loss of scientists to Britain - in particular, the tendency of postgraduates to seek research posts overseas - is virtually balanced by the number coming to work in the country from abroad.

The numbers involved have changed little. The new report, prepared with support from the Nuffield Foundation, found, for example, that the number of recently qualified postgraduates leaving to work overseas had risen slightly, from 13.4 to 13.5 per cent. The number of more senior staff leaving in the second period was 2.1 per cent, and heads of department 0.3 to 0.5 per cent.

The biggest change was in chemistry, where the number of departing $\mathrm{PhDs}$ rose from 12.0 to 16.2 per cent; in contrast, their peers in Earth sciences fell from 23.6 to 12.7 per cent, largely reflecting declining demand in the oil industry. In biochemistry, the emigration rate for new $\mathrm{PhDs}$ remained at about 19.0 per cent.

Nor has there been a significant change in the motivations to leave Britain - or for returning to it. Most scientists left for pro- fessional reasons, the most widely quoted grounds being enhanced career prospects and "a desire to widen experience"; 73 per cent of those coming back quoted unspecified personal reasons as a motivation, and 64 per cent a desire to return to British culture.

One novel finding of the report is the different statistics between men and women. The study found that, when compared to the total numbers of each category, women were about half as likely to emigrate as men but equally likely to come to Britain.

The biggest change since the mid-1980s has been the destination of those leaving Britain. The proportion taking up research posts elsewhere in Europe has risen from 22 to 31 per cent. In contrast, there has been an almost identical drop, from 63 to 53 per cent, in the proportion of emigrant scientists taking up positions in the United States.

The government has, perhaps inevitably, taken comfort from the fact that the braindrain does not seem to be getting any worse. Indeed, the report points out explicitly that those entering Britain's science and engineering base "seem to have been no more likely to emigrate during the past decade than they were during the previous decade."

But the report itself warns of the dangers of complacency. It points out for example that those leaving Britain tend to take up long-term positions abroad, returning only for personal reasons. In contrast, those arriving take short-term posts.

\section{Labour leader pledges support for LHC}

London. John Smith, the leader of Britain's opposition Labour Party was expected to confirm this week that, if elected, his party would create a single Ministry for Science, and to pledge support for the proposed Large Hadron Collider (LHC) at CERN

Smith also urged the government to take a new look at proposals first put forward two years ago to create so-called Faraday Centres, designed to bring together academic and industrial scientists.

These suggestions were due to be made to a meeting at Imperial College, London, held by the organization Save British Science. According to an advance text of his speech, Smith planned to use the occasion to criticize the impact on science of three beliefs held by the conservative government: the virtues of the market; that the public sector tends to do things less efficiently than the private sector; and the political need for massive cuts in public expenditure.

While adding his voice to the many who have attacked the short-term outlook of both British industry and financiers, Smith claimed that the government has yet to take
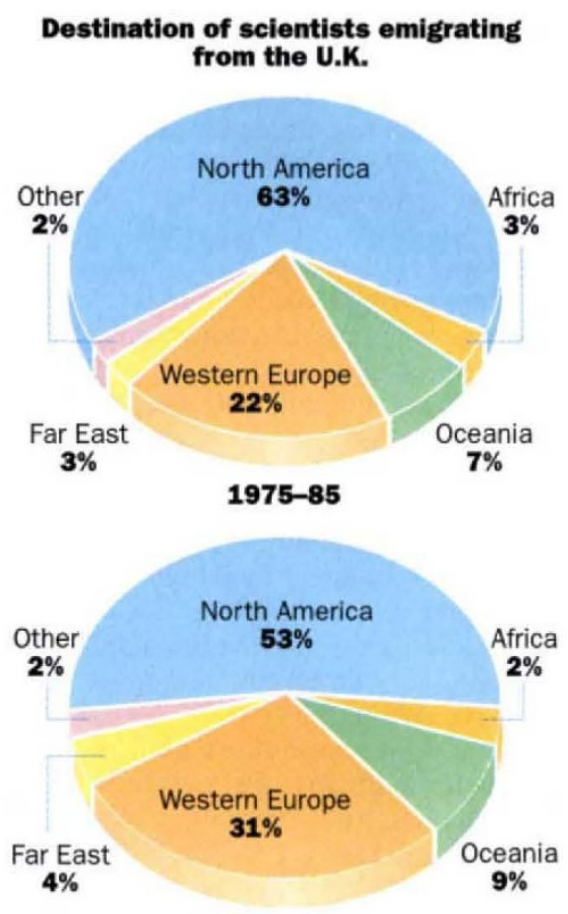

1984-92

"We should be careful not to draw too much comfort from the simple numerical head count" says Ian Nussey, chairman of SEPSU's management board, pointing to the growing number of Royal Society fellows with addresses outside Britain. Almost two-thirds of those replying to the survey felt that emigration was having an adverse effect on British science, and half of these felt that the effect was "serious".

David Dickson

such criticism fully on board. In particular, its approach to "technology foresight" appeared to be repeating the mistake of demanding "too rapid a pay-back".

The opposition is also keen to bring basic and applied research closer together, and would achieve this by creating "overlapping networks" in which scientists and members of the business and financial community would meet to exchange ideas. One way of achieving this would be through the so-called Faraday Centres; the question of how the academic and industrial research communities "has still not been properly addressed", Smith said.

More resources for direct government funding of research and development, and for the science base, must both be priorities, said Smith. Expecting doctoral students to live on as little as $£ 4,720$ a year, for example, is "little short of scandalous".

And he urged the government to increase its support for international projects such as the LHC. "If the British government wants Europe to lead the world, here is a project which it should be actively supporting." 